\title{
Pressure Monitoring of Intraneural an Perineural Injections Into the Median, Radial, and Ulnar Nerves; Lessons From a Cadaveric Study
}

\author{
Andrzej Krol ${ }^{1, *}$; Matthew Szarko ${ }^{2}$; Arber Vala $^{2}$; Jose De Andres ${ }^{3}$ \\ ${ }^{1}$ Department of Anaesthesia and Chronic Pain Service, St Georges Hospital, London, United Kingdom \\ ${ }^{2}$ St George's University of London, London, United Kingdom \\ ${ }^{3}$ Department of Anaesthesia Critical Care and Pain Management, School of Medicine, University of Valencia, General University Hospital, Valencia, Spain \\ ${ }^{*}$ Corresponding author: Andrzej Krol, Consultant Anesthetist in Department of Anaesthesia and Chronic Pain Service, St Georges Hospital, London SW17 oRE, United Kingdom. Tel: \\ +44-2086721255, Fax:+44-2087253135, E-mail: andrzej.krol@stgeorges.nhs.uk
}

Received: August 12, 2014; Revised: October 17, 2014; Accepted: November 4, 2014

\begin{abstract}
Background: Nerve damage after regional anesthesia has been of great concern to anesthetists. Various modalities have been suggested to recognize and prevent its incidence. An understudied area is the measurement of intraneural pressure during peripheral nerve blockade. Previous investigations have produced contradicting results with only one study being conducted on human cadavers.

Objectives: The purpose of this investigation was to systematically record intraneural and perineural injection pressures on the median, ulnar, and radial nerves exclusively as a primary outcome.

Materials and Methods: Ultrasonography-guided injections of $1 \mathrm{~mL}$ of $0.9 \% \mathrm{NaCl}$ over ten seconds were performed on phenol glycerine embalmed cadaveric median, ulnar, and radial nerves. A total of 60 injections were performed, 30 intraneural and 30 perineural injections. The injections pressure was measured using a controlled disc stimulation device. Anatomic dissection was used to confirm needle placement.

Results: Intraneural needle placement produced significantly greater pressures than perineural injections did. The mean generated pressures in median, radial, and ulnar nerves were respectively $29.4 \pm 9.3,27.3 \pm 8.5$, and $17.9 \pm 7.0$ pound per square inch $(\mathrm{psi})(1 \mathrm{psi}=$ $51.7 \mathrm{mmHg}$ ) for the intraneural injections and respectively $7.2 \pm 2.5,8.3 \pm 2.5$, and $6.7 \pm 1.8$ psi for perineural injections. Additionally the intraneural injection pressures of the ulnar nerve were lower than those of the median and radial nerves.

Conclusions: Obtained results demonstrate significant differences between intraneural and perineural injection pressures in the median, ulnar, and radial nerves. Intraneural injection pressures show low specificity but high sensitivity suggesting that pressure monitoring might be a valuable tool in improving the safety and efficacy of peripheral nerve blockade in regional anesthesia. Peripheral nerves "pressure mapping" hypothetically might show difference amongst various nerves depending on anatomic location, histologic structure, and ultrasonographic appearance.
\end{abstract}

Keywords: Injections; Pressure; Radial Nerves

\section{Background}

Following the introduction of the nerve stimulator 40 years ago (1) and two decades since the application of the ultrasonography (USG) into contemporary regional anesthesia (RA) practice (2), a consensus is yet to be reached on the level and methods of monitoring needed during nerve block to confirm exact needle placement. Although USG, nerve stimulator, injection pressure, and patient wakefulness have all been suggested, specific use and combination of these factors has not been accepted universally $(3,4)$. Reports of intraneural needle placement with no neurologic consequences have created much confusion and resulted in a plethora of papers regarding safety of intraneural needle placement during $\mathrm{RA}$, which is comprehensively reviewed by Sala-Blanch et al. (5). Overall incidence of nerve injury associated with RA has been estimated between 1:5000 and 1: 2500 (6-8). Its association with the final needle position is even less clear and since the incidence of injury is very low, these quoted studies with small numbers are not sufficient to guide us. Therefore, intraneural (beyond the epineurium) needle placement cannot be recommended ( 9 , 10) due to the potential risk of permanent nerve damage leading to disability as well as triggering litigation (11). As a result of clinical wisdom, a combination of USG, nerve stimulation, and injection pressure monitoring in awake patients was suggested for the early detection of intraneural needle placement and prevention of subsequent intraneural injection $(3,12)$. Using animal models to investigate the association between injection pressure and intraneural needle placement has produced conflicting results. Selander and Sjostrand (13) were the first to illustrate that intraneural injections would produce a sustained and elevated pressure increases. Furthermore Hadzic et al. (14) discovered that all intraneural injections were associated with high injection pressures of 25 to 45 pound per square inch (psi; each psi

Copyright (C) 2015, Iranian Society of Regional Anesthesia and Pain Medicine(ISRAPM). This is an open-access article distributed under the terms of the Creative Commons Attribution-NonCommercial 4.0 International License (http://creativecommons.org/licenses/by-nc/4.0/) which permits copy and redistribute the material just in noncommercial usages, provided the original work is properly cited. 
is almost equal to $51.7 \mathrm{mmHg}$ ) and produced persistent motor deficits in all cases with $>25$ psi. In addition, all perineural injections produced a much lower injection pressure of $\leq 4 \mathrm{psi}$. In contrast, studies by Altermatt et al. (15) and Lupu et al. (16) did not demonstrate a correlation between higher injection pressures and intraneural needle placement. These studies also failed to link intraneural injection to functional nerve injury or histologic evidence of intrafascicular injection. There is currently very limited human or cadaveric data regarding intraneural injection pressure (4). We are aware of a single study (17) on human cadavers where the brachial plexus roots in unembalmed human cadavers were injected and the pressure injection as well as the spread of the injected materials were recorded. The intraneural injection pressure was very high, with a mean of $48.9 \mathrm{psi}$, in comparison two control injections with needle inserted adjacent to the epineurium of $\mathrm{C} 6$ and $\mathrm{C} 7$ nerve root with pressure of 17.6 and 8.2 psi for 5 and $15 \mathrm{~mL}$ injected volume, respectively; however, this finding was not a primary focus of the investigation. Most recently, Gadsden et al. (18) demonstrated a higher opening injection pressure when the needle was in contact with nerve root but not beyond the epineurium in contrast with the consistently lower opening injection pressure when needle was $1 \mathrm{~mm}$ away from the brachial plexus roots during brachial plexus block.

\section{Objectives}

In light of these facts, we performed an independent investigation of USG-guided intraneural and perineural injections into the medial, radial, and ulnar nerves with the intention of recording and comparing intraneural and perineural values. We hypothesize that the intraneural injection pressure will be greater than the perineural injection pressure.

\section{Materials and Methods}

All of the cadaveric tissues were obtained and utilized in accordance with the Human Tissue Act (2004), which includes first person consent for cadaveric investigation. Cadaveric preservation involved the use of phenol and glycerol rather than formaldehyde, which allowed similar tissue mobility as in vivo conditions. A total of 60 injections were conducted using 12 cadaveric arms from six cadavers. Five cadavers were initially provided to perform bilateral radial, median, and ulnar nerve injections (30 intraneural and 30 perineural). In one cadaver, the radial nerve could not be identified on one side and in another one, an ulnar nerve injection measurement was missed due to investigator's error. As such, an extra cadaver was used to complete the sixty injections. In total, 20 injections were conducted for each of the radial, median, and ulnar nerves (10 intraneural and 10 perineural). All injections were performed at the level of the distal arm. Radial nerve was localized at the anterior compartment of the arm after leaving spiral groove between brachialis and brachioradialis muscle and before division into deep and superficial branch. Median nerve was identified medial to brachial artery in the antecubital fossa. Ulnar nerve lies most superficially under the skin, in compare to radial and median nerve, cranially to the medial epicondyle. An M-Turbo USG system (Sonosite-Fuji Inc, Bothell, WA, USA) was used with a linear 6 to $13 \mathrm{MHz}$ transducer L-38 for needle placement. After identifying a cross-sectional view of the nerves at the described level, an 80-mm, 22-G needle (Sonoplex, Pajunk, Melsungen, Germany) was inserted using an in plane technique. The perineural injection was performed within $1 \mathrm{~mm}$ to the epineurium as per standard peripheral nerve block to ensure free flow of solution. For intraneural injection, the needle was inserted into the clearly identifiable nerve structure as seen on USG and according to the current understanding of the concept (3). For intraneural needle placement, once the needle passed the epineurium, USG assessment could not differentiate between extrafascicular (interfascicular epineurium, perineurium) or intrafascicular needle placement (endoneurium, axons). USG images of both perineural and extraneural needle position were captured and stored. Solution spread for perineural injection and nerve swelling (change in cross-sectional area) for intraneural injection were not recorded as a video clips due to a small volume of injection $(1 \mathrm{~mL})$ and with the assumption that it would not add value to the investigation. After needle placement, $1 \mathrm{~mL}$ of $0.9 \% \mathrm{NaCl}$ was injected over ten seconds $(0.1 \mathrm{~mL} / \mathrm{sec})$ and the opening injection pressure was recorded in psi using a Controlled Disc Stimulation (CDS) device (Controlled Disc Stimulation, NeuroTherm, Middleton, MA, USA) (Figure 1).

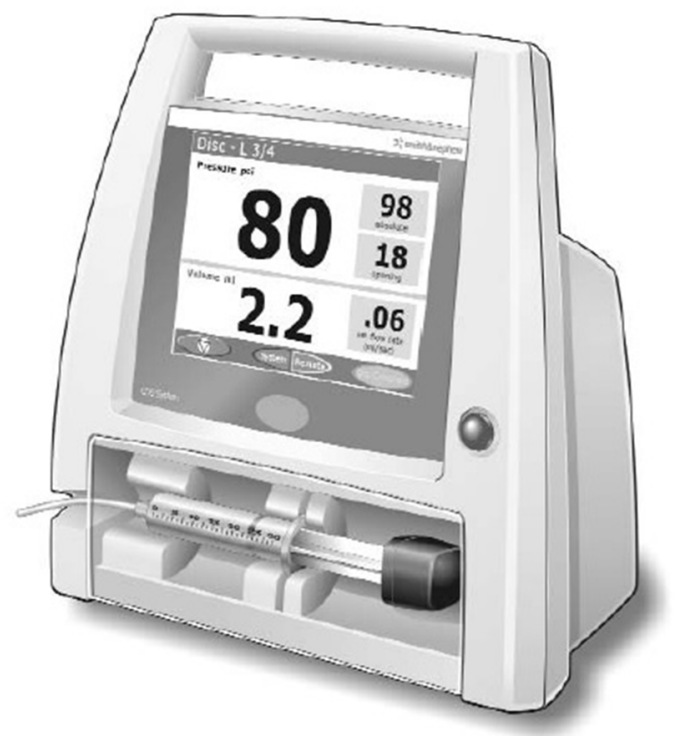

Figure 1. The Controlled Disc Stimulation Device 
We defined opening injection pressure as the pressure peak that followed the initiation of the injection. Most of the injections produced a similar pattern of a low initial pressure, increasing to a maximal "peak pressure" (opening injection pressure) and ended in a lower pressure. Some injections did not reach peak value within ten-second injection time. The CDS device was utilized as it is known to deliver precise pressure recordings in provocative discography: volume accuracy of $0.05 \mathrm{~mL}$, pressure accuracy of $\pm 5 \%$, and flow rate accuracy of $1.1 \%$ as per Operation/Service Manual (19). The NeuroTherm CDS system employs a syringe pump that delivers media in a controlled fashion, a syringe with an integrated pressure transducer, and a piece of software that allows the calculation of the pressure at the tip of the needle by accounting for the fluid dynamic variables between the transducer and the tip of the needle. The calculated pressure is displayed on the CDS screen. Data was recorded using a computer-based data acquisition system (LabView, USA). In this study, encountered fluid dynamics were described using the Navier-Stokes equation, which took the key variables affecting fluid behavior into account. The key variables were fluid viscosity $(\mathrm{cP})$, flow rate $(\mathrm{mL} / \mathrm{s})$, needle length (cm), needle gauge (ga), tubing length, and tubing diameter. To detect any difference in terms of needle length, we measured the baseline (needle open to air) pressure of injection of $1 \mathrm{~mL}$ of $0.9 \% \mathrm{NaCl}$ at a rate of $1 \mathrm{~mL}$ in ten seconds with 22-G needles of consecutively $100-\mathrm{mm}, 80-\mathrm{mm}$, and 50-mm lengths as these needle lengths are routinely used clinically. The tubing length was kept the same in each case.
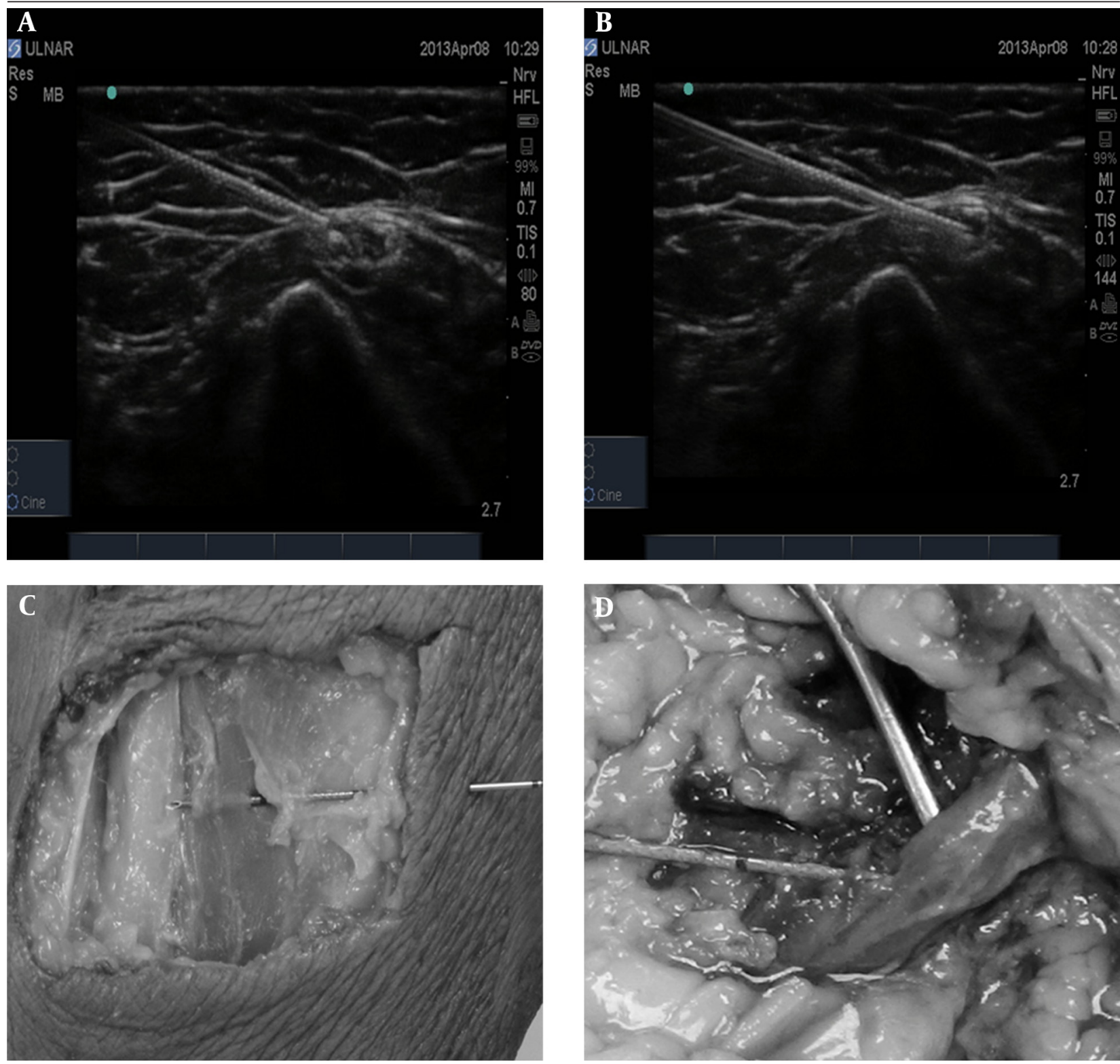

Figure 2. Illustrating the ultrasonography-guided needle placement (2A and 2B, perineural and intraneural injections, respectively) and the corresponding dissections to confirm the need position ( $2 \mathrm{C}$ and $2 \mathrm{D}$, perineural and intraneural injections, respectively) 
The present investigation chose the $80-\mathrm{mm}$ needle as it was most commonly used in clinical practice in our institution. Peripheral nerve block of median, ulnar, and radial nerve, selectively or in combination, often follows immediately infraclavicular brachial plexus block to speed up onset in desired distribution. Needles were left in situ after completing the injection and recording of injection pressure. The cadavers were subsequently dissected to confirm needle placement. The dissections confirmed needle placement and are illustrated together with the USG images in Figure 2. All injections were performed by main investigator (AK) with more than eight years of experience in USG-guided interventions. Injection pressures were recorded on CDS device by DD (David Drew Operator of CDS device (AK) being blinded to the needle position. All dissections were performed by MS and AV. The data was statistically analyzed using paired-samples $t$ tests to compare the intraneural and perineural values obtained from the same nerves. Significance was assumed at $\mathrm{P}<0.05$. All statistical analyses were conducted using GraphPad (version 6, USA).

\section{Results}

The baseline pressure of injection of $1 \mathrm{~mL}$ of $0.9 \%$
$\mathrm{NaCl}$ at a rate of $0.1 \mathrm{~mL} / \mathrm{sec}$ with $100-\mathrm{mm}, 80-\mathrm{mm}$, and 50-mm 22-G needles showed no difference in pressure values (Table 1). All of the cadaveric dissections confirmed that the needle was positioned correctly (Figure 2). The CDS graphs produced following the injection of $1 \mathrm{~mL}$ of $0.9 \% \mathrm{NaCl}$ in ten seconds are displayed in Figure 3. This data shows that intraneural placed needles produced a greater injection pressures in comparison to perineural injections across all three nerves. The means of generated pressures by intraneural and perineural injections into the median nerve were respectively $29.4 \pm 9.3$ and $7.2 \pm 2.5(\mathrm{P}<0.01)$.

Table 1. The Baseline Pressure of Injecting $1 \mathrm{~mL}$ of $0.9 \% \mathrm{NaCl}$ at a Rate of $0.1 \mathrm{~mL} / \mathrm{sec}$ With Different Length of 22-G Needles ${ }^{\text {a }}$

\begin{tabular}{lc}
\hline Needle Length, $\mathbf{m m}$ & Injection Pressure, psi \\
\hline $\mathbf{5 0}$ & 0.2 \\
$\mathbf{8 0}$ & 0.2 \\
$\mathbf{1 0 0}$ & 0.2 \\
\hline a Abbreviations: mm, millimeters; and Psi, pounds per square inch.
\end{tabular}

Table 2. The Intraneural and Perineural Opening Injections Pressures Obtained for the Median, Ulnar, and Radial Nerves When Injecting $0.9 \% \mathrm{NaCl}^{\mathrm{a}, \mathrm{b}}$

\begin{tabular}{|c|c|c|c|c|c|c|}
\hline \multirow[t]{3}{*}{ Side } & \multicolumn{6}{|c|}{ Opening Injection Pressure } \\
\hline & \multicolumn{2}{|c|}{ Median Nerve } & \multicolumn{2}{|c|}{ Radial Nerve } & \multicolumn{2}{|c|}{ Ulnar Nerve } \\
\hline & Intraneural & Extraneural & Intraneural & Extraneural & Intraneural & Extraneural \\
\hline \multicolumn{7}{|l|}{$\mathbf{1}$} \\
\hline Right & 25 & 10 & 23 & 8 & 13 & 6 \\
\hline Left & 20 & 7 & 20 & 9 & 16 & 10 \\
\hline \multicolumn{7}{|l|}{2} \\
\hline Right & 40 & 6 & 33 & 12 & 9 & 5 \\
\hline Left & 22 & 5 & 24 & 8 & & \\
\hline \multicolumn{7}{|l|}{3} \\
\hline Right & 48 & 6 & 21 & 4 & 15 & 6 \\
\hline Left & 38 & 10 & & & 26 & 7 \\
\hline \multicolumn{7}{|l|}{4} \\
\hline Right & 26 & 5 & 18 & 6 & 27 & 6 \\
\hline Left & 22 & 5 & 32 & 6 & 21 & 5 \\
\hline \multicolumn{7}{|l|}{5} \\
\hline Right & 26 & 6 & 26 & 9 & 12 & 9 \\
\hline Left & 27 & 12 & 47 & 12 & 12 & 5 \\
\hline \multicolumn{7}{|l|}{6} \\
\hline Left & & & 29 & 9 & 28 & 8 \\
\hline Mean \pm SD & $29.4 \pm 9.299$ & $7.2 \pm 2.529$ & $27.3 \pm 8.538$ & $8.3 \pm 2.54$ & $17.9 \pm 7.03$ & $6.7 \pm 1.7669$ \\
\hline
\end{tabular}

${ }^{\mathrm{a}}$ In all cases, $1 \mathrm{~mL}$ of $0.9 \% \mathrm{NaCl}$ was injected at the rate of $0.1 \mathrm{~mL} / \mathrm{sec}$.

$\mathrm{b}$ All pressures are expressed in psi (pound per square inches). 
Krol A et al.

The means of generated pressures in the radial nerve through intraneural and perineural injections were respectively $27.3 \pm 8.5$ and $8.3 \pm 2.5 \mathrm{psi}(\mathrm{P}<0.01)$. The means of generated pressures in the ulnar nerve by intraneural and perineural injections were $17.9 \pm 7.0$ and $6.7 \pm 1.8 \mathrm{psi}$
$(\mathrm{P}<0.01)$ (Figure 4). All perineural injections produced a pressure of $<12$ psi. In contrast, all intraneural injections pressures for median nerve and all of that for radial nerves, except one measurement, were $>20$ psi. These results are illustrated in Table 2 and Figure 4.

Figure 3. The Measurements Obtained From the Controlled Disc Stimulation Device

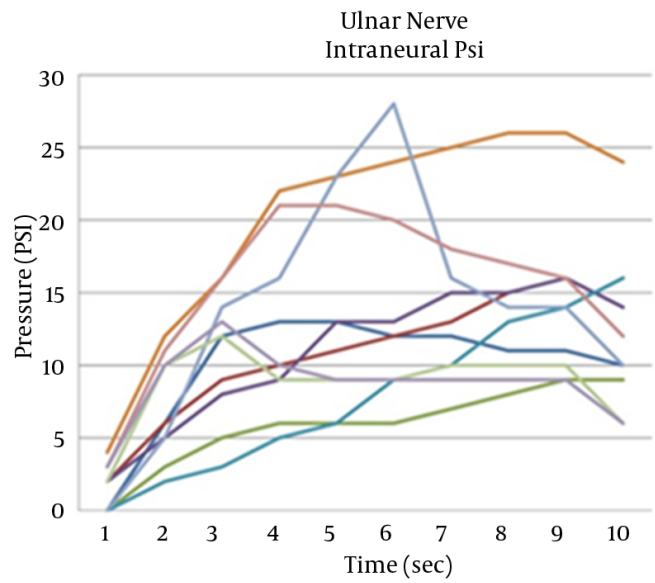

Median Nerve

Intraneural Psi

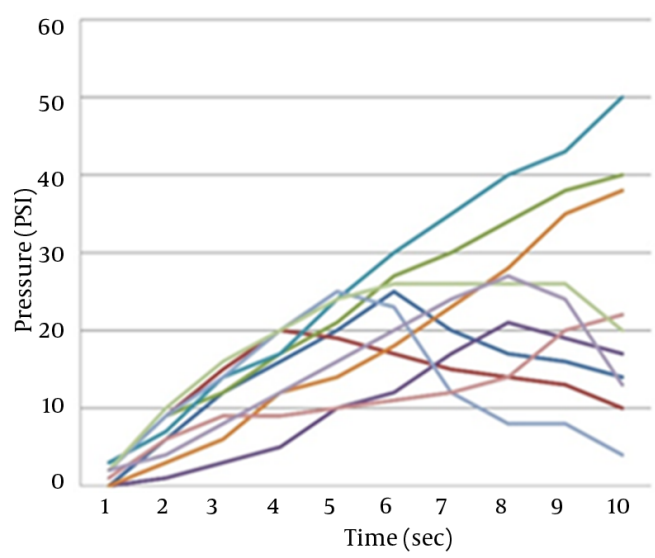

Radial Nerve

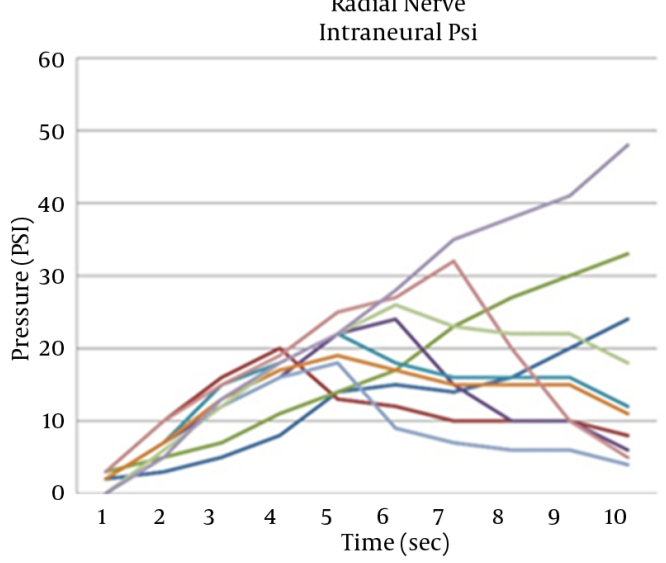

- Nerve 1

- Nerve 2

Nerve 3

- Nerve 4

- Nerve 5

Nerve 6

Nerve 7

Nerve 8

Nerve 9

- Nerve 10

- Nerve 1

- Nerve 2

- Nerve 3

-Nerve 4

- Nerve 5

- Nerve 6

- Nerve 7

- Nerve 8

-Nerve 9

- Nerve 10

-Nerve 1

- Nerve 2

- Nerve 3

-Nerve 4

- Nerve 5

- Nerve 6

- Nerve 7

- Nerve 8

- Nerve 9

— Nerve 10

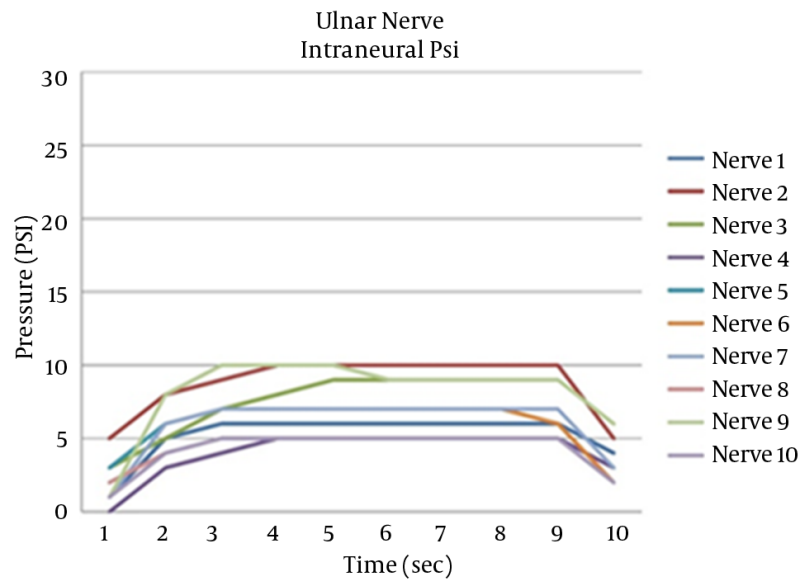

Median Nerve

Intraneural Psi

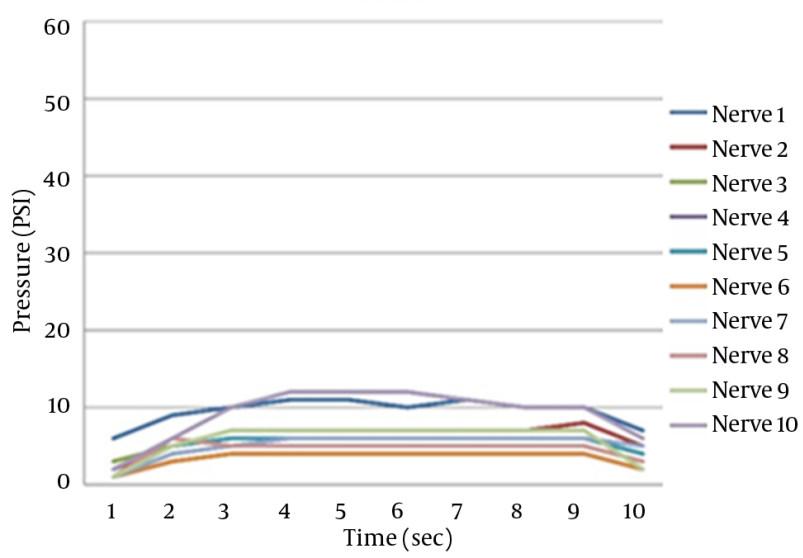

Radial Nerve

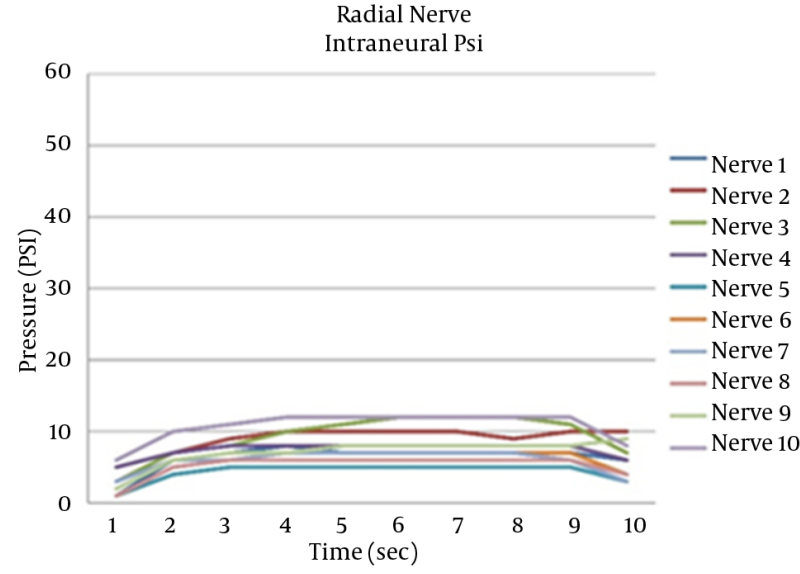

Intraneural and perineural injection pressures are shown on the left and right columns, respectively. 
Figure 4. The Bar Graph Shows the Peak Intraneural and Extraneural Pressures of the Median, Radial, and Ulnar Nerves Following Injections of 1.0 $\mathrm{mL}$ Saline With a Flow Rate of $0.1 \mathrm{~mL} / \mathrm{sec}$ using an 80-mm 22-G Needle

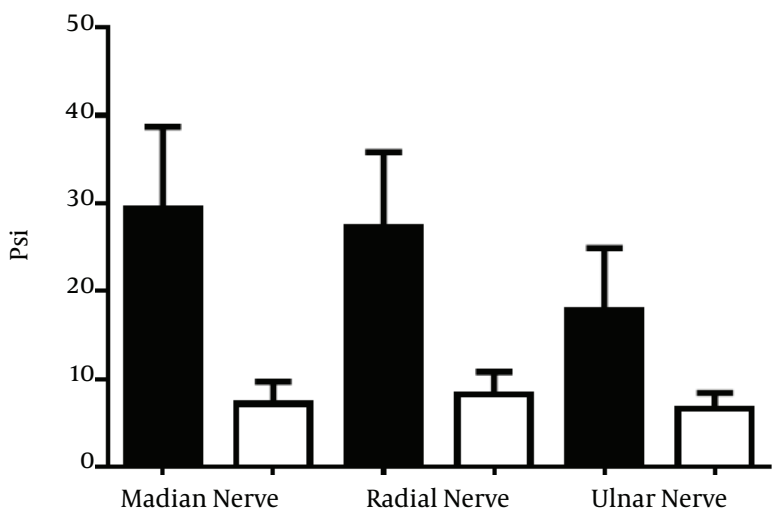

The data are statistically significant across all three nerves; the P values are $<0.01$ for all three nerves, ie. median, radial, and ulnar (a paired-samples t test was used; $\mathrm{n}=10$ ).

\section{Discussion}

The obtained results demonstrate a statistically significant difference between intraneural and perineural injection pressures in the median, ulnar, and radial nerves in soft-preserved cadaveric tissues. Additionally, considerable variation between the intraneural injection pressures of the ulnar nerve was discovered in comparison to the radial and median nerves. For six out of ten ulnar nerves intraneural injections, the injection pressure was $<20$ psi. The present investigation confirms previously identified positive correlations between increased injection pressures and intraneural placement $(13,18,20)$. Orebaugh et al. (17) conducted a study in which unembalmed cadaveric nerve roots were injected intraneurally at the $\mathrm{C} 6$ and $\mathrm{C} 7$ level and the pressure of injection as well as the spread of the injected materials was recorded. Their results' were in concordance with our findings and showed that intraneural needle placement produces an elevated injection pressure with a mean time to peak injection pressure of $10.3 \pm 3.3$ seconds. Their values, however, were significantly greater than ours were (mean of 48.9 vs 24.9 psi). The most likely explanation of the difference between our studies results involves the histologic variation between the peripheral nerves and the cervical roots with respect to fascicle number and size and the amount of connective tissue within the nerve. USG commonly shows a different appearance between hypoechoic (black appearance) proximally to hyperechoic (honeycomb appearance) distally in peripheral nerves (9). The histologic variation in peripheral nervous structure has recently been demonstrated by Reina et al. (21) and offered as an explanation for the sporadic severity and range of nervous damage following intraneural injections in $\mathrm{RA}$. Al- though histologic microscopic examinations determining the exact needle position within the nerve (whether intrafascicular or extrafascicular) were not conducted, the contraindication of advancing a needle beyond epineurium $(9,10)$ made this unnecessary. The pressure monitoring device used in their studies was PV350 (Fluke Corporation, Everett, Washington), which is a pressure/ vacuum transducer and differs to the CDS device used in our study, which is used to measure injection pressures during intradiscal injections. A probable explanation for the difference in magnitude of the opening injection pressures is that the greater values were achieved in their study though the use of a greater injection rate and volume of fluid. Orebaugh et al. (17) used $5 \mathrm{~mL}$ of fluid with a rate of $5 \mathrm{~mL}$ per 15 seconds $(0.33 \mathrm{~mL} / \mathrm{sec})$ in comparison to $1 \mathrm{~mL}$ of $\mathrm{NaCl}$ with a rate of $0.1 \mathrm{~mL} / \mathrm{sec}$ in our study. Introducing larger volume with faster rate into an enclosed space, such as the cervical nerve roots, might explain the greater increase in pressure. The embalming of cadavers with phenol and glycerol in comparison to unembalmed cadaveric tissues might also be an important factor. The data also showed considerable variation between the ulnar nerve intraneural injection pressures in comparison to the radial and median nerves. This might suggests some histologic differences between the epineurium, intrafascicular, and extrafascicular anatomy between these nerves. The authors acknowledge this to be an area that warrants further investigation. We have chosen median, radial and ulnar nerve for our initial studies for various reasons; first, it is common in our institution to supplement supraclavicular/infraclavicular/axillary block with abovementioned nerves depending on required field of surgery to reinforce and speed up block onset. Second, at the investigated level, nerves are in isolation, clearly identified on USG, and can be blocked selectively. Third, all three nerves were easy to dissect at the described position. We admit that nerve structures at location such as cervical roots, trunks, divisions, cord, and nerves of lumbar and sacral plexus such as femoral and sciatic are subject of our next investigation to produce "map of injection pressure". One of the main limitations of our study was that the results were obtained from soft embalmed cadavers, which might not reflect the rigor of the human tissues. Additionally, the current study injected $1 \mathrm{~mL}$ of $0.9 \% \mathrm{NaCl}$ at a rate of $0.1 \mathrm{~mL} / \mathrm{sec}$ for 10 seconds. The 1-mL volume was chosen as it is common in clinical practice to inject 1-mL aliquots to assess the visible spread and rely on assistant/device feedback measuring resistance to injection. Chan et al. (22) confirmed that USG is able to detect $1 \mathrm{~mL}$ of injected material. We are aware, however, that this injection rate was much slower than usual clinical practice and the injected volume was much lower. It has been chosen deliberately hypothesizing that if we were able to prove statistically significant difference between intraneural and perineural pressure injection of such a small volume and rate, it would be even more significant for higher rates and volumes. We consider it rather as a 
Krol A et al.

strength and not weakness of our study. In their study design, Hadzic et al. (14) injected $4 \mathrm{~mL}$ of $2 \%$ lidocaine at the rate $1 \mathrm{~mL}$ per 15 seconds ( $0.66 \mathrm{~mL} / \mathrm{sec})$. In another study, the rate of injection created by anesthetists during simulated nerve block was recorded as between 2 to $6 \mathrm{~mL} / \mathrm{sec}$ (23). The most recent conducted animal studies have contradicted the association between increased injection pressures and intraneural needle placement. Lupu et al. (16) used the open model of the porcine median nerve and direct needle placement to inject up to $20 \mathrm{~mL}$ of $2 \%$ lignocaine with $5 \mu \mathrm{g} / \mathrm{mL}$ (1:200.000) adrenaline or until an extraneural leakage was seen on USG. The injection of local anesthetic induced histologic evidence of inflammation in seven out of ten swine; however, none of the specimens exhibited functional neurologic deficits. The mean value obtained for the intraneural injections was $5.1 \pm 2.9$ psi. Altermatt et al. (15) conducted a similar study in which, $4 \mathrm{~mL}$ of India ink was injected. The mean intraneural injection pressure was 7.4 psi with a wide range (0.07-31.5 psi). The injection pressure was recorded every two seconds in this study. Unfortunately the rate of fluid injection was not described in the methodology. However, one must consider the differences in methodology between these papers. In both of Lupu et al. and Altermatt et al. $(15,16)$ works, the injection pressure measurements were the secondary focus. Different injected materials as well as different needle length and gauge size were used in all the studies. All of these factors contribute to fluid dynamics in the Navier-Stokes equation. This makes comparing and extrapolating our findings difficult. An in-depth discussion about the limitations of the above articles is beyond the scope of this paper. In detailed review regarding needle to nerve proximity and its consequences in animal studies, Macfarlane et al.(24) concluded that high injection pressure is neither sensitive nor specific to detect intraneural injection but low injection pressure might be useful for its negative predictive value. At the time of conducting the study, there was no commercial device in Europe to monitor injection pressure during regional blocks. If pressure monitoring is to be widespread and we are going to move from dual to triple monitoring, the device should be easy to use, portable, reliable, and affordable.

In conclusion, we have demonstrated that intraneural injections produce greater injection pressure in comparison to perineural injections, supporting our hypothesis. We used a small volume $(1 \mathrm{~mL})$ of saline solution $(0.9 \%$ $\mathrm{NaCl}$ ) for a longer (10 seconds) than traditional injection time, which was capable of demonstrating statistically significant differences between intraneural and perineural injections. Our study showed that pressure monitoring has a high sensitivity as all extraneural injection pressure were $<12 \mathrm{psi}$, which was in concordance with the results by Selander and Sjostrand (13) and Hadzic et al. (14). We also conclude that pressure monitoring has a low specificity, as false positive readings might occur once the needle tip is obstructed by sitting directly against a bone, ligament, tendon, or the nerve (18). We acknowledge that more studies are needed to investigate the complicated association between needle placement and injection pressure as histologic differences might exist among various peripheral nerves warranting "pressure mapping" to elucidate potential clinical implications. Injection pressure recording, which also includes volume, rate of injection, type of solution, needle size, length, tip shape, and model type (open-close), should be part of a robust protocol.

\section{Acknowledgements}

We would like to thank Mr. David Drew from Neurotherm for helping us to collect the data for this study and providing CDS system for pressure monitoring.

\section{References}

1. Montgomery SJ, Raj PP, Nettles D, Jenkins MT. The use of the nerve stimulator with standard unsheathed needles in nerve blockade. Anesth Analg. 1973;52(5):827-31.

2. Kapral S, Krafft P, Eibenberger K, Fitzgerald R, Gosch M, Weinstabl C. Ultrasound-guided supraclavicular approach for regional anesthesia of the brachial plexus. Anesth Analg.1994;78(3):507-13.

3. Neal JM, Wedel DJ. Ultrasound guidance and peripheral nerve injury: is our vision as sharp as we think it is? Reg Anesth Pain Med. 2010;35(4):335-7.

4. Gadsden J, McCally C, Hadzic A. Monitoring during peripheral nerve blockade. Curr Opin Anaesthesiol. 2010;23(5):656-61.

5. Sala-Blanch X, Vandepitte C, Laur JJ, Horan P, Xu D, Reina MA, et al. A practical review of perineural versus intraneural injections: a call for standard nomenclature. Int Anesthesiol Clin. 2011;49(4):1-12.

6. Brull R, McCartney CJ, Chan VW, El-Beheiry H. Neurological complications after regional anesthesia: contemporary estimates of risk. Anesth Analg. 2007;104(4):965-74.

7. Barrington MJ, Watts SA, Gledhill SR, Thomas RD, Said SA, Snyder GL, et al. Preliminary results of the Australasian Regional Anaesthesia Collaboration: a prospective audit of more than 7000 peripheral nerve and plexus blocks for neurologic and other complications. Reg Anesth Pain Med. 2009;34(6):534-41.

8. Liu SS, Ngeow JE, Yadeau JT. Ultrasound-guided regional anesthesia and analgesia: a qualitative systematic review. Reg Anesth Pain Med. 2009;34(1):47-59.

9. Boezaart AP. That which we call a rose by any other name would smell as sweet-and its thorns would hurt as much. Reg Anesth Pain Med. 2009;34(1):3-7.

10. Auroy Y, Narchi P, Messiah A, Litt L, Rouvier B, Samii K. Serious complications related to regional anesthesia: results of a prospective survey in France. Anesthesiology. 1997;87(3):479-86.

11. Lee LA, Posner KL, Cheney FW, Caplan RA, Domino KB. Complications associated with eye blocks and peripheral nerve blocks: an american society of anesthesiologists closed claims analysis. Reg Anesth Pain Med. 2008;33(5):416-22.

12. Reiss W, Kurapati S, Shariat A, Hadzic A. Nerve injury complicating ultrasound/electrostimulation-guided supraclavicular brachial plexus block. Reg Anesth Pain Med. 2010;35(4):400-1.

13. Selander D, Sjostrand J. Longitudinal spread of intraneurally injected local anesthetics. An experimental study of the initial neural distribution following intraneural injections. Acta Anaesthesiol Scand.1978;22(6):622-34.

14. Hadzic A, Dilberovic F, Shah S, Kulenovic A, Kapur E, Zaciragic A, et al. Combination of intraneural injection and high injection pressure leads to fascicular injury and neurologic deficits in dogs. Reg Anesth Pain Med. 2004;29(5):417-23.

15. Altermatt FR, Cummings TJ, Auten KM, Baldwin MF, Belknap SW, Reynolds JD. Ultrasonographic appearance of intraneural injections in the porcine model. Reg Anesth Pain Med.2010;35(2):203-6. 
16. Lupu CM, Kiehl TR, Chan VW, El-Beheiry H, Madden M, Brull R Nerve expansion seen on ultrasound predicts histologic but not functional nerve injury after intraneural injection in pigs. Reg Anesth Pain Med. 2010;35(2):132-9.

17. Orebaugh SL, Mukalel JJ, Krediet AC, Weimer J, Filip P, McFadden $\mathrm{K}$, et al. Brachial plexus root injection in a human cadaver model: injectate distribution and effects on the neuraxis. Reg Anesth Pain Med. 2012;37(5):525-9.

18. Gadsden JC, Choi JJ, Lin E, Robinson A. Opening injection pressure consistently detects needle-nerve contact during ultrasound-guided interscalene brachial plexus block. Anesthesiology. 2014;120(5):1246-53.

19. Smith\&Nephew.. Controlled Disc Stimulation System Operation Service Manual 2005-2008. 2008. Available from: www.smithnephew.com.

20. Vuckovic I, Hadzic A, Dilberovic F, Kulenovic A, Mornjakovic Z, Zulic I, et al. Detection of neurovascular structures using injection pressure in blockade of brachial plexus in rat. Bosn J Basic Med Sci. 2005;5(3):79-85.

21. Reina MA, Arriazu R, Collier CB, Sala-Blanch X, Izquierdo L, de Andres J. Electron microscopy of human peripheral nerves of clinical relevance to the practice of nerve blocks. A structural and ultrastructural review based on original experimental and laboratory data. Rev Esp Anestesiol Reanim. 2013;60(10):552-62.

22. Chan VW, Brull R, McCartney CJ, Xu D, Abbas S, Shannon P. An ultrasonographic and histological study of intraneural injection and electrical stimulation in pigs. Anesth Analg. 2007; 104(5):1281-4.

23. Claudio R, Hadzic A, Shih H, Vloka JD, Castro J, Koscielniak-Nielsen $\mathrm{Z}$, et al. Injection pressures by anesthesiologists during simulated peripheral nerve block. Reg Anesth Pain Med. 2004;29(3):201-5.

24. Macfarlane AJ, Bhatia A, Brull R. Needle to nerve proximity: what do the animal studies tell us? Reg Anesth Pain Med. 2011; 36(3):290-302. 